\title{
Immunomagnetic $T$ cell capture from blood for PCR analysis using microfluidic systems
}

\author{
Vasile I. Furdui and D. Jed Harrison \\ Department of Chemistry, University of Alberta, Edmonton, AB, Canada T6G 2 G2. \\ E-mail: Jed.Harrison@ualberta.ca; Fax: +1-780-492-8231; Tel: +1-780-492-2790
}

Received 21st June 2004, Accepted 24th August 2004

First published as an Advance Article on the web 11th November 2004

\begin{abstract}
A one-step immunomagnetic separation technique was performed on a microfluidic platform for the isolation of specific cells from blood samples. The cell isolation and purification studies targeted $\mathrm{T}$ cells, as a model for low abundance cells (about 1:10,000 cells), with more dilute cells as the ultimate goal. $\mathrm{T}$ cells were successfully separated on-chip from human blood and from reconstituted blood samples. Quantitative polymerase chain reaction analysis of the captured cells was used to characterize the efficiency of $\mathrm{T}$ cell capture in a variety of flow path designs. Employing many (4-8), $50 \mu \mathrm{m}$ deep narrow channels, with the same overall cross section as a single, $3 \mathrm{~mm}$ wide channel, was much more effective in structuring dense enough magnetic bead beds to trap cells in a flowing stream. The use of 8-multiple bifurcated flow paths increased capture efficiencies from $\sim 20$ up to $37 \%$, when compared to a straight 8 -way split design, indicating the value of ensuring uniform flow distribution into each channel in a flow manifold for effective cell capture. Sample flow rates of up to $3 \mu \mathrm{L} \min ^{-1}$ were evaluated in these capture beds.
\end{abstract}

\section{Introduction}

Microfluidic systems appear to offer a powerful means to automate and miniaturize sample preparation for genetic assays and for clinical diagnostics in samples such as blood..$^{1-3}$ However, while analyses of small volumes on a microchip are readily performed, the concentration or number of copies per $\mathrm{mL}$ of a target analyte in blood can be so low that relatively high volumes $(10-1000 \mu \mathrm{L})$ must be processed. ${ }^{4}$ This leads to a need for two separate stages in a micro total analysis system $(\mu$-TAS $),{ }^{3}$ one that can process and concentrate samples from a relatively high volume, and another, smaller volume stage, that performs biochemical assays such as immunoassays or the polymerase chain reaction (PCR). The design of the first, large volume stage has not been extensively explored, but is a critical component of an overall $\mu$-TAS concept for clinical diagnostics. In this report we describe the study of appropriate flow paths that can be combined with magnetically trapped bead beds to capture rare cells from blood samples, to perform the sample clean-up that is often needed for analysis by PCR. ${ }^{5-7}$

A large number of chip-based methods for genetic analysis have been reported, predominantly involving integration of PCR and separation of the PCR product. ${ }^{8-10}$ With the development of microchip methods for RNA or DNA sample preparation, ${ }^{11-13}$ PCR $^{14-17}$ and on-chip hybridization, ${ }^{18,19}$ it has become clear that integrating the cell capture and concentration steps within a $\mu$-TAS system remains a bottleneck. Microfiltration ${ }^{20}$ and dielectrophoresis ${ }^{11,21}$ have been used to integrate blood sample preparation with PCR on microfabricated devices. These studies showed the challenge associated with blood sample preparation for PCR. The microfilters were prone to clogging by blood samples, while the dielectrophoresis studies used only diluted or resuspended blood cells within a specific separation buffer, that was required to adjust the conductivity. As an alternative, paramagnetic beads offer a means to form an immunocapture bed to isolate rare cells from blood. These beds would be less susceptible to the challenges blood creates, because the beds can be formed and then released again in large channels that do not plug easily.
Magnetic bead beds have attracted interest and were used successfully for dynamic DNA hybridization ${ }^{19}$ and mRNA isolation ${ }^{13}$ within a microfluidic device. A self-assembled magnetic bead-bed was proposed for cell sorting ${ }^{22}$ in order to obtain a more controllable, compact magnetic bed. The integration of magnetic trap actuator coils within a microfluidic device was also demonstrated by Ahn et al. ${ }^{23}$ Recently, we reported on the use of a magnetic bead capture chip, in which antibody coated paramagnetic beads where first mixed off-chip with blood samples, then introduced into the chip, where the target cells were captured, washed and isolated from blood. ${ }^{24}$ Liu et al. have reported a similar approach, in which the PCR step was also integrated on-chip. ${ }^{3}$ These developments are promising, but it would be more convenient if the immunocapture reaction could also be performed in the microfluidic system, so that no external sample preparation was required.

In this study human $\mathrm{T}$ cells (or the $\mathrm{T}$ cell derived Jurkat cell line) were used as the initial model of rare cells in blood, although more dilute sample analyses are ultimately contemplated. Protein A/anti-human CD3 paramagnetic beads were first introduced into the chips and captured in a field generated by an external magnet. A blood sample was then introduced, $\mathrm{T}$ cells were captured and rinsed clean, collected at the chip outlet and moved to a different module (off-chip in this case) for subsequent analysis. This report focuses on the most appropriate design choices for the creation of microfluidic bead capture beds, when applied to blood samples that need to be several $\mu \mathrm{L}$ or more in volume.

\section{Experimental}

\section{Chip preparation}

Device layouts were fabricated on $4^{\prime \prime} \times 4^{\prime \prime}(0.54 \mathrm{~mm}$ thick $)$ 0211 glass (Corning, NY, USA) at Micralyne, Edmonton, AB, Canada or at the University of Alberta Nanofab, as previously described, ${ }^{25}$ with $1.5 \mathrm{~mm}$ diam. access holes and $50-100 \mu \mathrm{L}$ fluid reservoirs. Y-intersection devices ${ }^{13,26}$ (Fig. 1) with coated walls were isotropically etched ( $\mathrm{HF}: \mathrm{HNO}_{3}$ etchant) to 10,30 and $50 \mu \mathrm{m}$ depths using a $100 \mu \mathrm{m}$ wide photomask feature. 


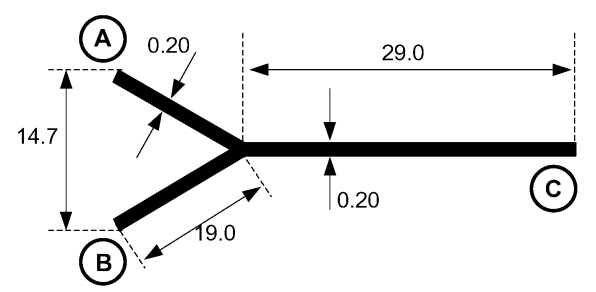

Fig. 1 Layout of the Y-intersection device used for immunomagnetic separation of blood cells. Dimensions (in $\mathrm{mm}$ ) correspond to the photomask features. A and B represent the inlets and C is the outlet. The Y-device used for coated wall cell capture used a $0.1 \mathrm{~mm}$ channel width.

Y-devices used for magnetic bead beds were etched $70 \mu \mathrm{m}$ deep, starting from a mask feature width of $200 \mu \mathrm{m}$ (capture cross section $2.17 \times 10^{-2} \mathrm{~mm}^{2}$ ). The FAT 3000 device, illustrated in Fig. 2, had seven different flow manifolds, each with a total manifold mask feature width of $3000 \mu \mathrm{m}$, isotropically etched in glass to a $50 \mu \mathrm{m}$ depth, giving various cross sections. The names for the manifolds were derived from the flow splitting used (designated A, B, C or D) and the number of channels in the capture area $(1,2,4$ or 8$)$.

A PHD 70-2001 syringe pump (Harvard Apparatus, SaintLaurent, QC, Canada) with a $100 \mu \mathrm{L}$ SGE gas-tight syringe (Supelco, Sigma-Aldrich Canada, Oakville, ON) in withdrawal

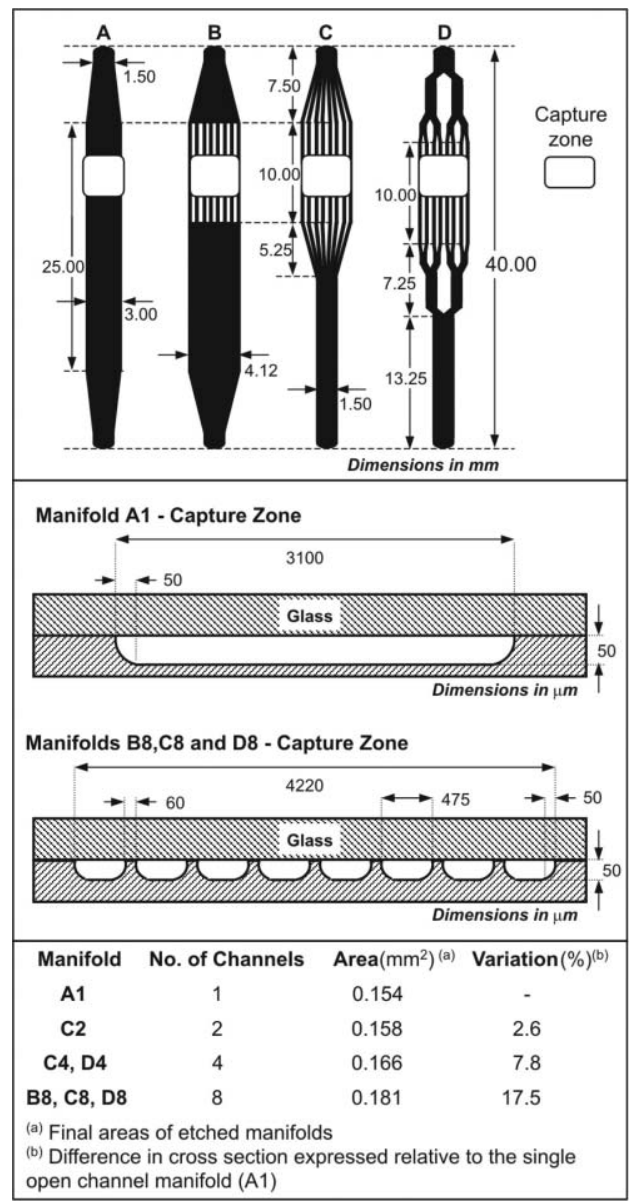

Fig. 2 Layout of the four different types of the manifold designs on the FAT 3000 device $(\mathrm{A}, \mathrm{B}, \mathrm{C}$ and D). The manifolds had $1 \times 3 \mathrm{~mm}$, $2 \times 1.5 \mathrm{~mm}, 4 \times 0.75 \mathrm{~mm}$ or $8 \times 0.375 \mathrm{~mm}$ channels in the capture zone, with gaps between the channels of $0,1.120,0.374$ and $0.160 \mathrm{~mm}$, respectively. Dimensions in the upper image $(\mathrm{mm})$ correspond to the photomask features. Channels were etched isotropically $50 \mu \mathrm{m}$ deep in $0.54 \mathrm{~mm}$ thick Corning 0211 glass. Lower images show the crosssectional profiles in the capture zone of the manifolds A1, B8, C8 and D8 of the FAT 3000 device after etching (in $\mu \mathrm{m}$ ). mode (i.e. suction) pumped liquids through the chips. Devices were rinsed using technical grade $70 \%$ ethanol. Channels were pre-conditioned with $1 \%$ bovine serum albumin (BSA, SigmaAldrich Oakville, ON, Canada) to block non-specific adsorption $\left(1 \mu \mathrm{L} \mathrm{min}{ }^{-1}\right.$ for $1 \mathrm{~min}$, then $0.25 \mu \mathrm{L} \mathrm{m^{-1 }}$ for $30 \mathrm{~min}$, Y-device, or $10 \mu \mathrm{L} \mathrm{min}{ }^{-1}$ for $1 \mathrm{~min}$, then $2.5 \mu \mathrm{L} \mathrm{min}^{-1}$ for 5 min, FAT 3000), and filled with Dulbecco's phosphate buffered saline (PBS, Invitrogen, Burlington, ON, Canada).

$\mathrm{T}$ cell capture on channel walls was performed in $\mathrm{Y}$-devices first conditioned (stopped flow mode) with $70 \% \mathrm{HNO}_{3}(1 \mathrm{~h})$, $2 \mathrm{M} \mathrm{H}_{2} \mathrm{SO}_{4}(20 \mathrm{~min})$ and $1 \mathrm{M} \mathrm{NaOH}(1 \mathrm{~h})$. The best results were obtained by then coating (stopped flow mode) with $20 \mu \mathrm{g} \mathrm{mL}^{-1}$ Protein A (Sigma-Aldrich) in PBS $(1 \mathrm{~h})$, followed by $20 \mu \mathrm{g} \mathrm{mL}^{-1}$ anti-human CD3 (in PBS, $30 \mathrm{~min}$, clone HIT3a, BD PharMingen Canada, Mississauga, ON) and 1\% BSA (in PBS, $30 \mathrm{~min}$ ).

For magnetic bead beds, Protein A/anti-human CD3 paramagnetic particles were introduced into channels and captured magnetically with a $6 \mathrm{~mm}$ diameter $\mathrm{NdFeB}$ permanent magnet (Edmund Industrial Optics, Barrington, NJ, USA), Fig. 3. Anti-human CD3 was first loaded onto 1-2 $\mu \mathrm{m}$ diam., Protein A-coated, paramagnetic particles (Polysciences, Warrington, PA) by mixing $10 \mu \mathrm{L}$ of the particle suspension (containing $133 \mu \mathrm{g}$ solids covered with $1 \mu \mathrm{g}$ Protein A) with $400 \mu \mathrm{L}$ of $20 \mu \mathrm{g} \mathrm{mL} \mathrm{mL}^{-1}$ anti-human CD3 in an Eppendorf tube for $10 \mathrm{~min}$, pelleting with a magnetic particle concentrator $\mathrm{MPC}^{\mathbb{R}}-\mathrm{E}-1$ (Dynal Biotech), washing $3 \mathrm{X}$ with $100 \mu \mathrm{L}$ PBS, then resuspending in $10 \mu \mathrm{L}$ PBS.

\section{Samples}

Jurkat cells (ATCC No. TIB-152, clone E6-1, T cell leukemia, human) were maintained in RPMI 1640 buffer supplemented with $10 \%$ fetal bovine serum, $1 \% \mathrm{~L}$-glutamine and $2 \%$ antibiotic antimycotic solution (Sigma-Aldrich), stabilized in a humidified atmosphere with $8 \% \mathrm{CO}_{2}$ at $37{ }^{\circ} \mathrm{C}$ provided by a NuAire US Autoflow (NU-4750) Automatic CO2 water-jacketed incubator (Plymouth, MN, USA). Cells were counted with a hemacytometer, and viability was determined using Trypan Blue $0.4 \%$ solution (both Sigma-Aldrich). Cultures were

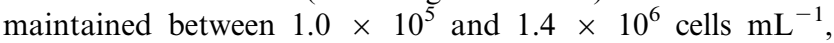

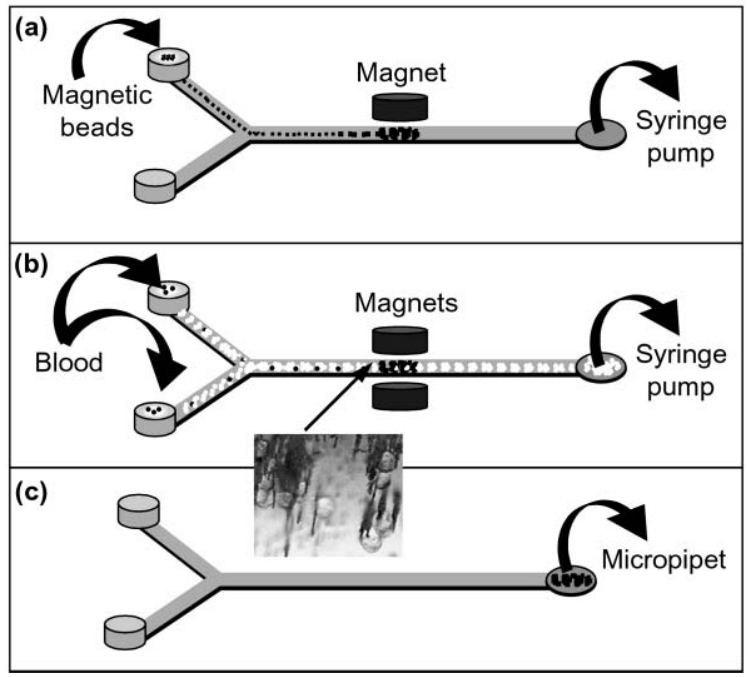

Fig. 3 Immunomagnetic separation of $\mathrm{T}$ cells using $\mathrm{Y}$-intersection device; (a) syringe pump draws Protein A/anti-human CD3 magnetic beads into the channel for capture with a magnet; (b) blood samples are introduced from both channels, $\mathrm{T}$ cells are captured with magnets above and below, then washed with RPMI 1640; (c) magnets were removed and captured cells and magnetic beads were transferred from the outlet with a micropipet. Inset shows T cells captured by beads in a magnetic field. Beads show as dark streaks, cells as translucent circles (cells are about $15 \mu \mathrm{m}$ in diam.) 
with $91 \%-94 \%$ viable cells. Serial dilutions were performed with supplemented RPMI 1640.

Heparinized human blood samples $(1 \mathrm{~mL})$ were from a pooled, anonymous blood bank of patients from the Cross Cancer Institute (Edmonton, AB, Canada). Aliquots of $2.00 \pm$ $0.05 \mu \mathrm{L}(\mathrm{RSD}=2.5 \%)$ of human blood were analyzed on-chip in the Y-device. Aliquots of $2.00 \mu \mathrm{L}(1070 \pm 104$ Jurkat cells, $\mathrm{RSD}=9.7 \%$ ) of reconstituted horse blood were analyzed in FAT 3000. Concentrated horse red blood cells $\left(1-2 \times 10^{10}\right.$ cells $\mathrm{mL}^{-1}$, HemoStat Labs, Dixon, CA, USA), free of white blood cells, were mixed with $1-10 \times 10^{5}$ Jurkat cells $\mathrm{mL}^{-1}$ suspended in supplemented RPMI 1640 to obtain reconstituted blood samples with $\geqslant 10,000$ horse red blood cells for every Jurkat cell and a 1:1 supplemented RPMI 1640 media to horse plasma ratio. This mixture gave similar physical properties to human blood samples, but allowed a quick and precise preparation of samples with a well controlled, stable number of target Jurkat (T) cells for quantitative analysis.

\section{Chip operating procedures}

Human blood samples were used to evaluate magnetic bead capture beds in $70 \mu \mathrm{m}$ deep Y-devices. Bead beds were prepared as described, a second magnet was placed under the chip opposite the first, as shown in Fig. 3, then a $2 \mu \mathrm{L}$ aliquot of blood was slowly layered on the bottom of reservoirs A and B, each pre-filled with $40 \mu \mathrm{L}$ of supplemented RPMI 1640, and pumped through the chip for $30 \mathrm{~min}$ at $0.25 \mu \mathrm{L} \mathrm{min}^{-1}$, followed by a PBS rinse for $20 \mathrm{~min}$ at $1 \mu \mathrm{L} \mathrm{min}{ }^{-1}$. The magnets were removed, the beads were pumped to the outlet reservoir, then collected by pipet for PCR analysis. Reconstituted horse blood samples were used to evaluate magnetic bead capture beds in $50 \mu \mathrm{m}$ deep FAT 3000 devices. The same procedure as above was followed, except the sample was delivered to the bed at $3 \mu \mathrm{L} \mathrm{min}{ }^{-1}$ for $3 \mathrm{~min}$, and the PBS rinsing step used $10 \mu \mathrm{L} \mathrm{min}{ }^{-1}$ for 3-20 min.

\section{Off-chip PCR and electrophoretic analysis of captured cells}

DNA from cells was isolated during a 5 min incubation using a Dynabeads ${ }^{\mathbb{R}}$ DNA DIRECT ${ }^{\circledR}$ kit (Dynal Biotech, Lake Success, NY, USA). The cells were mixed with $200 \mu \mathrm{L}$ of Dynabeads in Dynal lysing buffer, in $1.5 \mathrm{~mL}$ siliconized Eppendorf tubes. The standards contained between 10\% and $200 \%$ of the Jurkat or $\mathrm{T}$ cells analyzed on-chip. The supernatant was removed after $2 \mathrm{~min}$ in a magnetic particle concentrator, followed by 3-200 $\mu \mathrm{L}$ aliquots of washing buffer (Dynal). The beads were placed in $20 \mu \mathrm{L}$ resuspension buffer, and DNA was released by incubating $5 \mathrm{~min}$ at $65{ }^{\circ} \mathrm{C}$. The supernatant was transferred to a $0.2 \mathrm{~mL}$ PCR tube, while the beads (Dynabeads and Protein A) remained in the magnetic particle concentrator.

The V-J junction of the T cell receptor (TCR) $\gamma$ gene was amplified by PCR in the absence of paramagnetic beads, using a Progene Techne thermal cycler (Mandel Scientific Company Ltd., Guelph, ON, Canada), and PCR primers (V1, 5'TACATCCACTGGTACCTACACCA-3', J1/2, ${ }^{\prime}$, CCCGTCG ACTACCTTGGAAATGTTGTATTCTTC- $\left.3^{\prime}\right)^{27}$ from Invitrogen (Burlington, ON, Canada). Samples analyzed on Y-devices and FAT 3000 devices were processed with PCR kit I (Applied Biosystems, GeneAmp ${ }^{\mathbb{R}}$ PCR Core Reagents) and PCR kit II (Invitrogen, Platinum ${ }^{\circledR}$ PCR SuperMix), respectively. PCR was performed simultaneously for each batch of samples and standards using DNase/RNase-free distilled water (Invitrogen), to minimize run variation.

For the Y-device a $20 \mu \mathrm{L}$ aliquot was amplified, following the suppliers procedures. Relative blood standards consisting of 0.50 to $4.00 \mu \mathrm{L}$ of blood, withdrawn from the same stock blood sample analyzed on-chip, was analyzed by PCR simultaneously with the chip treated sample. Signal from the sample could then be correlated with the different blood volumes to obtain an effective volume for the chip-prepared sample, to thus determine cell capture efficiency relative to direct analysis of a sample aliquot.

For FAT 3000 studies a $10 \mu \mathrm{L}$ aliquot was amplified, following suppliers procedures. Standards were prepared by delivery of various volumes of reconstituted horse blood, to calibrate the number of cells captured on chip from a $2 \mu \mathrm{L}$ aliquot of reconstituted blood.

The $300 \mathrm{bp}$ PCR product obtained from samples and standards was analyzed at $10 \mathrm{kV}\left(370 \mathrm{~V} \mathrm{~cm}^{-1}\right)$ by capillary gel electrophoresis (CGE), using a Beckman P/ACE 5010, with a $488 \mathrm{~nm}$ laser fluorescence detector. A physical gel containing $0.4 \% \mathrm{HPMC}$ and $0.5 \mu \mathrm{g} \mathrm{mL}^{-1}$ ethidium bromide in $0.5 \times \mathrm{TBE}$ (Tris-Boric acid-EDTA) running buffer (Amersham) was used to fill a $27 \mathrm{~cm}$ long, $50 \mu \mathrm{m}$ id fused silica capillary. An initial $1 \mathrm{~s}$ hydrodynamic injection $(3.45 \mathrm{kPa})$ of pure water increased the size and precision of peak heights. ${ }^{28,29}$ Samples were injected at $5 \mathrm{kV}$ for $5 \mathrm{~s}$. Quantitative results are the average of 4 sequential electropherograms.

\section{Results and discussion}

Several different formats for the fluidic design of a cell capture system were evaluated. The first was a simple, coated-wall device with an open-tubular flow path. Difficulties with this approach led us to then investigate magnetically trapped bead beds for cell capture, which are routinely used off-chip for sample enrichment and specific target isolation. Initially, a single-channel Y-device was used to evaluate cell capture efficiency, but this system gave low sample throughput. Then a series of larger volume, more complex, flow paths were evaluated, in order to establish the most appropriate flow path for formation of a bead bed with good capture efficiency and better throughput.

\section{Channel wall capture of sample in a Y-intersection device}

An antibody-coated channel wall provides the simplest form of capture device design, however, there are a number of competing design challenges that limit performance of such a design. Because only the wall can trap cells, the capillary diameter should be small enough to allow frequent wall contact, but large enough to avoid plugging. High flow rates are desirable to allow large sample throughput, but low shear forces (low linear velocity) are required to maximize cell capture. In a series of qualitative studies with anti-human CD3 coated Y-devices, all the devices tested allowed flow when used with Jurkat cell suspensions $\left(\sim 10^{6}\right.$ cells $\left.\mathrm{mL}^{-1}\right)$. However, when blood samples were introduced, only the deepest etch ( $50 \mu \mathrm{m}, 0.109 \mathrm{~mm}^{2}$ cross section) gave devices that maintained flow with human blood samples. To evaluate shear force effects on capture, the wall surfaces were first saturated by passing a $10^{5} \mathrm{~T}$ cells $\mathrm{mL}^{-1}$ suspension through the $50 \mu \mathrm{m}$ deep device for an extended period, then subjected to a $30 \mathrm{~s}$ flow burst at a given flow rate, and the remaining cells were counted. Cell counts of $149,52,6$, and 0 cells $/ 0.06 \mathrm{~mm}^{2}$ remained after exposure to flow rates of $1.25,5,50$ and $125 \mu \mathrm{L} \mathrm{min}{ }^{-1}$. While the lowest flow rate did allow the capture and retention of cells, the need to use $50 \mu \mathrm{m}$ deep channels meant that many cells never came into contact with the chip walls, so that the capture efficiency was severely limited. Further, coating the walls with antibody did not give highly reproducible cell capture efficiency. Consequently, the capture of cells on a dispersed magnetic bead bed within a large channel appeared to be an attractive alternative. 


\section{Magnetic bead bed capture of sample in a Y-intersection device}

Magnetically captured bead beds provide a high surface area for the convenient capture and release of cells within a fluidic device. Initial formation of the bead bed is an important step in preparing the device for sample capture and enrichment. Bead capture was maximised through the use of an asymmetric magnetic field, achieved by placing a magnet on only one side of the chip. In a simple Y-channel device, Fig. 1, efficiencies of about $100 \%$ bead capture were achieved at bead loading flows of $100 \mu \mathrm{L} \mathrm{min}{ }^{-1}$ (average linear velocity of $154 \mathrm{~mm} \mathrm{~s}^{-1}$ ) in channels $70 \mu \mathrm{m}$ deep and $340 \mu \mathrm{m}$ wide at the top of the etched surface $\left(0.0217 \mathrm{~mm}^{2}\right.$ cross section). We selected $50 \mu \mathrm{L} \mathrm{min}{ }^{-1}$ to deliver $2 \mu \mathrm{L}$ of antibody loaded beads (in $40 \mu \mathrm{L}$ PBS), since this required less than $30 \mathrm{~s}$ for bead introduction. Semi-quantitative observation with a microscope showed that the majority of cells (Jurkat, $6.0 \times 10^{5}$ cells $\mathrm{mL}^{-1}, 93 \%$ viability) were easily captured when flow rates of $0.1-1 \mu \mathrm{L} \mathrm{min}{ }^{-1}$ were used. Above these flow rates the captured cell counts decreased with increasing rate, due either to the short time of contact with the beads, or the higher shear rates. These experiments established that a flow rate of $0.25 \mu \mathrm{L} \mathrm{min}{ }^{-1}$ (average linear velocity of $190 \mu \mathrm{m} \mathrm{s}^{-1}$ ) provides a reasonable capture rate for T cells, so this flow rate was employed for all studies on the Y-device.

The capture efficiency of the Y-device was tested using $2 \mu \mathrm{L}$ human blood samples containing about $3400 \mathrm{~T}$ cells. Cells were captured on preformed bead beds, then collected from the device and their DNA analyzed by PCR, along with a set of standards. A T cell receptor $\gamma$ gene was amplified simultaneously from sample and standards. Relative standards of the same blood sample were prepared off-chip using between $25 \%$ and $200 \%$ of the volume analyzed on-chip. This set of standards provides calibration of the PCR performance as a function of the total number of $\mathrm{T}$ cells in a given blood aliquot. It allows a comparison of the signal obtained from cells captured on-chip with those analyzed directly in the blood, providing a measure of the chip capture efficiency for $\mathrm{T}$ cells. The PCR product was analyzed by capillary gel electrophoresis (CGE). The calibration curves of peak height versus the volume of blood used were approximately linear, but slightly better curve fits (judged by $r^{2}$ values) were obtained from log-log plots. (A given set of blood sample standards had an intercept of -0.577 and a slope of $0.868\left(r^{2}=0.989\right)$.) The $2 \mu \mathrm{L}$ sample processed on-chip gave a signal corresponding to $0.835 \mu \mathrm{L}$ of blood, indicating a $\mathrm{T}$ cell capture efficiency of $42 \pm 4 \%$.

These experiments establish the ability to pre-form a bead capture bed for T cells, and then use the bed to capture T cells from a blood sample with a reasonable efficiency. However, the low flow rates used to effect good capture mean that only very small sample volumes can be processed conveniently. For example, a $2 \mu \mathrm{L}$ sample introduction, followed by a $2 \mu \mathrm{L}$ wash would take a minimum of $16 \mathrm{~min}$ at $0.25 \mu \mathrm{L} \mathrm{m^{-1 }}{ }^{-1}$. Thus extension of the approach to larger flow beds is necessary.

\section{Increased sample volume treatment in a FAT 3000 device}

The most appropriate approach to increasing sample capacity without drastic increases in linear flow velocity and shear force is to increase the volume of the capture bed. The flow path design for an efficient magnetic bead capture bed could take many forms, and it was not clear which would give the optimal capture efficiency. The device we named FAT 3000, Fig. 2, was designed to investigate seven different flow manifolds, each intended to have a total channel width of $3000 \mu \mathrm{m}$, and a cross section about 10 times larger than the Y-device, yielding ten times higher volume flow rates. Every manifold consisted of an inlet port, a splitting scheme, followed by a capture area and a channel to connect at the outlet port. The larger the flow manifold, the more opportunity for channelling to occur in the bead bed (temporary open flow channels formed within the bead bed), leading to lower capture efficiencies due to reduced contact between beads and cells. At the same time, the greater the number of channels in a manifold the greater will be the possibility for differing flow rates in different channels. Thus the number of channel splittings, and the shape of the flow splitters was investigated. Typical structures are illustrated in Fig. 2. (The $\sim 1: 1$ aspect ratio associated with glass etching gave cross-sections between each capture manifold that differed by up to $17.5 \%$, expressed relative to manifold A1, as shown in Fig. 2.)

The cell capture efficiency of the FAT 3000 manifolds was tested using reconstituted horse blood samples, spiked with human $\mathrm{T}$ cells (Jurkat cell line), and the number of cells captured was analysed using a hot-start PCR kit. These samples provided an accurately quantifiable number of target cells in each sample. Magnetic bead beds were first formed as described for the Y-device, using instead $5 \mu \mathrm{L}$ of bead suspension. Using a flow rate of $3 \mu \mathrm{L} \min ^{-1}$, a $2 \mu \mathrm{L}$ horse blood sample was introduced into a manifold, washed with PBS, and then the magnetic bead bed was released and transferred to the outlet reservoir for collection, PCR amplification and CGE analysis. A calibration curve for horse blood samples with $\mathrm{T}$ cell content varying from 10-40\% of the sample introduced on-chip is shown in Fig. 4. A linear fit to the logarithmic plot gave an intercept of -2.80 and a slope of 0.879 , with an $r^{2}$ of 0.997 .

Fig. 5 shows the measured capture efficiencies for the seven different manifolds. The $17.5 \%$ range in channel cross sections led to a range in average linear flow velocities between 250 and $320 \mu \mathrm{m} \mathrm{s}^{-1}$, which are within a factor of 1.7 of the flow rate used in testing the single channel Y-device $\left(190 \mu \mathrm{m} \mathrm{s}^{-1}\right)$. Comparing the results obtained on manifolds B8, C8 and D8, which have the same cross-sectional area $\left(0.181 \mathrm{~mm}^{2}\right)$, it can be concluded that the stepwise bifurcation design of manifold D8 gives a higher efficiency than a simple splitter design, because of a more effective distribution of the bead and cell flow streams. The same trend was observed comparing the efficiencies obtained on manifolds C4 and D4 (cross-sectional area of $0.166 \mathrm{~mm}^{2}$ ). Manifolds B and C immediately split the flow at the entrance, whereas manifold $\mathrm{D}$ uses repeated bifurcations to split the flow. The latter design ensures that each of the two

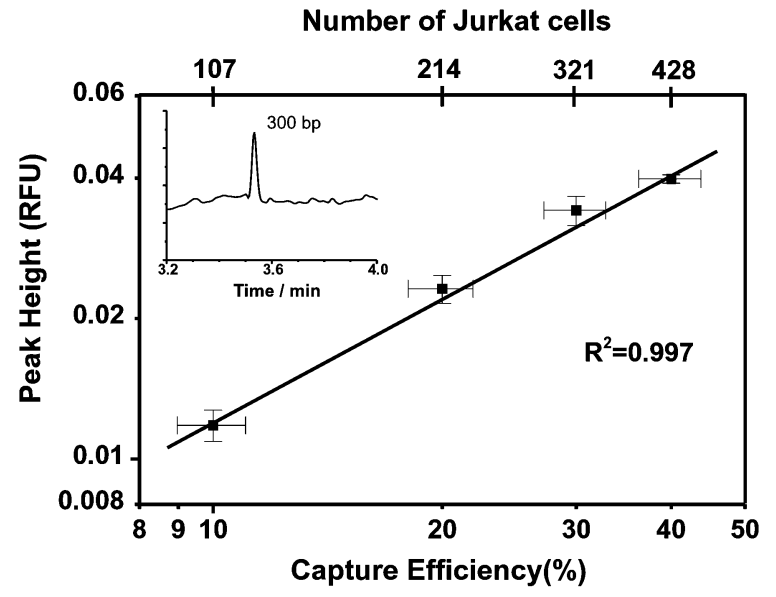

Fig. 4 Calibration curve for 300 bp PCR product. Inset shows typical electrophoresis peak for 300 base pair T-cell marker. A log-log plot of peak height versus the number of Jurkat cells in the standard (various standard volumes used) correlated peak height with Jurkat cell capture efficiency. Jurkats from a $2 \mu \mathrm{L}$ volume of the same reconstituted blood, were captured in the FAT 3000 manifolds ( $50 \mu \mathrm{m}$ depth), followed by off-chip extraction of DNA, and calibration for capture efficiency using this data set. Error bars show the SD. 


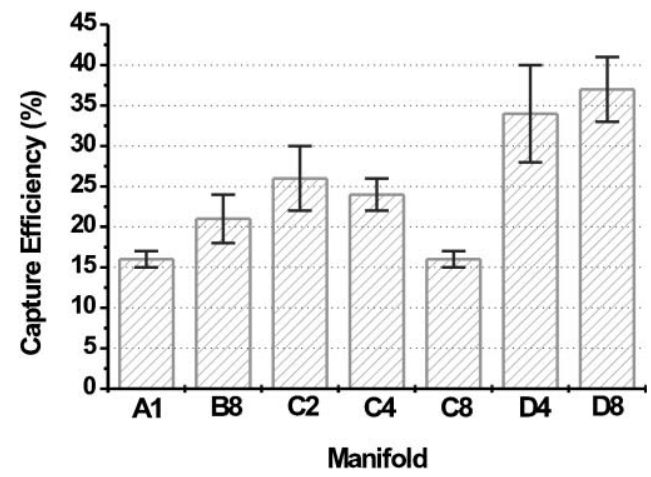

Fig. 5 Capture efficiency determined from PCR analysis (performed simultaneously) of samples captured in all seven manifolds of the FAT 3000 device $(50 \mu \mathrm{m}$ depth $)$.

paths downstream of a split have the same linear velocity profile at their entrance, so that each will receive an equal flow, in contrast to the situation with manifolds $\mathrm{B}$ or $\mathrm{C}$. Flow rate differences will lead to differences in the amount of beads trapped in each channel, and in the subsequent flow of sample through each bead bed, which could lead to inefficient capture in some of the flow paths. The results in Fig. 5 also show that multiple-channel bead beds provide better capture efficiency than one or two channel manifolds of the same cross section. Notably, even halving the channel size ( $c f$. A1 versus $\mathrm{C} 2$ ) in a manifold is enough to considerably improve capture efficiency. Visual inspection suggests this improved performance in narrower channels is because the bead beds formed are more uniform, and have a lower tendency to exhibit channelling through the beds that can "short circuit" cell capture. A reproducibility study $(n=4)$ of cell capture from reconstituted horse blood showed a range of up to $9 \%$ from day to day, but the trends between flow designs shown in Fig. 5 remained completely consistent.

\section{Conclusions}

This study provides a comparative evaluation of open tubular capture beds with magnetically trapped bead capture beds for the trapping and enrichment of relatively rare cells in blood samples. While the open tubular design allowed high flow rates, the associated shear stress prevented effective cell retention on the walls. More importantly, the need for 50-70 $\mu \mathrm{m}$ deep channels to prevent plugging by blood meant that too few of the cells came into contact with the walls, reducing trapping efficiency significantly. The magnetic bead bed approach provides a means to increase the capture surface area and place cells and surfaces in closer proximity. The use of a magnetically captured bed also allows the cells to be readily released again after washing, for further sample processing. As anticipated, wider channels gave reduced sample processing time in the bead bed, while still maintaining low enough shear stresses to retain captured cells. However, the poor performance of a single, wide channel (manifold A1) compared to the Y-device or to the other manifolds, shows that employing many, narrower channels is much more effective in structuring dense enough magnetic bead beds to trap the cell streams. The use of multiple bifurcated flow paths increased capture efficiencies from $\sim 20$ up to $37 \%$, compared to a straight 8 -way split design, indicating the value of ensuring uniform flow distribution into each channel in a flow manifold for effective cell capture.

\section{Acknowledgements}

Financial support from the Defense Advanced Research Projects Agency and Defence Research Development Canada Suffield is acknowledged. We are grateful to the University of Alberta for support of the NanoFab Lab. We thank L. Pilarski for arranging blood samples and D. R. Bundle for use of the cell culture facility.

\section{References}

1 P. A. Auroux, D. Iossifidis, D. R. Reyes and A. Manz, Anal. Chem., 2002, 74, 2637.

2 N. H. Chiem and D. J. Harrison, Clin. Chem., 1998, 44, 591.

3 R. H. Liu, J. Yang, R. Lenigk, J. Bonanno and P. Grodzinski, Anal. Chem., 2004, 76, 1824.

4 K. E. Petersen, W. A. McMillan, G. T. A. Kovacs, M. A. Northrup, L. A. Christel and F. Pourahmadi, Biomed. Microdev., 1998, 1, 71.

5 A. Akane, K. Matsubara, H. Nakamura, S. Takahashi and K. Kimura, Forensic Sci., 1994, 39, 362.

6 W. A. Al-Soud and P. Radstrom, J. Clin. Microbiol., 2001, 39, 485.

7 P. Singleton, DNA methods in clinical microbiology, Kluwer Academic Publishers, 2000.

8 J. Cheng, M. A. Shoffner, G. E. Hvichia, L. J. Kricka and P. Wilding, Nucl. Acids Res., 1996, 24, 380.

9 C. S. Effenhauser, G. J. Bruin and A. Paulus, Electrophoresis, 1997, 18, 2203.

10 A. T. Woolley, K. Lao, A. N. Glazer and R. A. Mathies, Anal. Chem., 1998, 70, 684.

11 J. Cheng, E. L. Sheldon, L. Wu, A. Uribe, L. O. Gerrue, J. Carrino, M. J. Heller and J. P. O'Connell, Nat. Biotechnol., 1998, 16, 541.

12 B. H. Weigl, R. L. Bardell, N. Kesler and C. J. Morris, Fresenius' J. Anal. Chem., 2001, 371, 97.

13 G. Jiang and D. J. Harrison, Analyst, 2000, 125, 2176.

14 J. Khandurina, T. E. McKnight, S. C. Jacobson, L. C. Waters, R. S. Foote and J. M. Ramsey, Anal. Chem., 2000, 72, 2995.

15 A. T. Woolley, D. Hadley, P. Landre, A. J. deMello, R. A. Mathies and M. A. Northrup, Anal. Chem., 1996, 68, 4081.

16 Y. Liu, D. Ganser, A. Schneider, R. Liu, P. Grodzinski and N. Kroutchinina, Anal. Chem., 2001, 73, 4196.

17 E. T. Lagally, P. C. Simpson and R. A. Mathies, Sens. Actuators B, 2000, 63, 138.

18 M. J. Heller, Annu. Rev. Biomed. Eng., 2002, 4, 129.

19 Z. H. Fan, S. Mangru, R. Granzow, P. Heaney, W. Ho, Q. Dong and R. Kumar, Anal. Chem., 1999, 71, 4851.

20 P. Wilding, L. J. Kricka, J. Cheng, G. Hvichia, M. A. Shoffner and P. Fortina, Anal. Biochem., 1998, 257, 95.

21 Y. Huang, K. L. Ewalt, M. Tirado, R. Haigis, A. Forster, D. Ackley, M. J. Heller, J. P. O'Connell and M. Krihak, Anal. Chem., 2001, 73, 1549.

22 C. Goubault, J.-L. Viovy and J. Bibette, Micro Total Analysis Systems, Nara, Japan, 2002, p. 844.

23 C. H. Ahn, M. G. Allen, W. Trimmer, Y.-N. Jun and S. Erramilli, J. Microelectromech. Syst., 1996, 5, 151.

24 V. I. Furdui, J. K. Kariuki and D. J. Harrison, J. Micromech. Microeng., 2003, 13, S164.

25 Z. H. Fan and D. J. Harrison, Anal. Chem., 1994, 66, 177.

26 H. Salimi-Moosavi, R. Szarka, P. Andersson, R. Smith and D. J. Harrison, Micro Total Analysis Systems, Banff, AB, Canada, 1998, p. 69.

27 M. Chhanabhai, S. A. Adomat, R. D. Gascoyne and D. E. Horsman, Am. J. Clin. Pathol., 1997, 108, 295.

28 R.-L. Chien and D. S. Burgi, J. Chromatogr., 1991, 559, 141.

29 K. J. Ulfelder, H. E. Schwartz, J. M. Hall and F. J. Sunzeri, Anal. Biochem., 1992, 200, 260. 